\title{
Reorganização dos Serviços de Saúde: Algumas Considerações Acerca da Relação entre a Descentralização, Autonomia Local e a Participação do Cidadão
}

\author{
The Reorganization of Health Services: Reflections on the Relationship \\ Between Decentralization, Local Autonomy and Citizens' Participation
}

\author{
Virginia Gawryszewski ${ }^{1}$
}

GAWRYSZEWSKI, V. The Reorganization of Health Services: Reflections on the Relationship Between Decentralization, Local Autonomy and Citizens' Participation. Cad. Saúde Públ., Rio de Janeiro, 9 (2): 210-215, Apr/Jun, 1993.

This paper discusses certain historical and theoretical aspects pertaining to the concepts of decentralization, local autonomy, and citizens' participation in studies on the reorganization of health services. Further studies should be undertaken to identify determinants of and limits to the reorganization of health services, greater local autonomy and citizens' participation. Various hypotheses and future courses of study are proposed.

Key words: Reorganization of Health Services; Decentralization of Health Services

\section{INTRODUÇÃO}

As mudanças que vêm ocorrendo nas formas de intervenção dos serviços de saúde, como conseqüência das mudanças que vêm sendo realizadas na sociedade brasileira, apontam para a necessidade de redefinição das atuais formas organizativas, que tradicionalmente apresentam características centralizadoras e, conseqüentemente, autoritárias e verticalizantes. Os desvios típicos desta estrutura centralizada vêm sendo, ao longo dos anos, objeto central de estudo por parte de autores tanto da área de Políticas Sociais como da área de Planejamento em Saúde. Estes estudos têm dado ênfase aos determinantes políticos e econômicos que originam a característica centralizada dos serviços, apontando para contradições nos elementos de sua padronização e aparente eficiência burocrática. Identificam, também, caminhos alternativos que se dirigem para as propostas de descentralização dos serviços, dotando-os de

\footnotetext{
${ }^{1}$ Departamento de Administração e Planejamento em Saúde da Escola Nacional de Saúde Pública. Rua Leopoldo Bulhões, 1480, $7^{\circ}$ andar, Rio de Janeiro, RJ, 21041-210, Brasil.
}

poder para redirecionar a sua prática. Os estudos diretamente relacionados à organização dos serviços de saúde vêm sendo uma preocupação crescente na área de Saúde Coletiva, ganhando maior expressão a partir de 1986, com a VIII Conferência Nacional de Saúde, como puderam testemunhar o I, II e III Congressos Brasileiros de Saúde Coletiva, realizados em 1986, 1989 e 1992, respectivamente.

A VIII Conferência Nacional de Saúde, ao deliberar pela reorientação do sistema de saúde, baseando-se nos princípios da descentralização e do fortalecimento dos níveis periféricos, através de uma maior autonomia na tomada de decisões em relação à própria prestação de serviços, abre caminho para propostas de reorganização dos serviços, cujas bases deverão estar ligadas ao processo de descentralização, à autonomia local e à participação do cidadão.

A Constituição brasileira, promulgada em 1988, na Seção II, capítulo II, "Da Seguridade Social”, consolida os princípios da VIII Conferência Nacional de Saúde, definindo as diretrizes básicas de um Sistema Único, diretrizes estas que englobam a descentralização e a participação da comunidade. Entretanto, a implementação do novo sistema fica dependente 
das interpretações conjunturais dos atuais governantes, que apresentam propostas de modelos já ultrapassados e que foram historicamente ineficazes na solução dos problemas de saúde da população brasileira.

A tendência nacional (ainda que em experiências limitadas) é na direção da implementação de um sistema nacional de saúde com características descentralizadas, no sentido de proporcionar maior eficácia ao conjunto de serviços prestados à população.

Tomando emprestada de Marx a frase "a humanidade só levanta problemas que é capaz de resolver e, assim, numa observação atenta, descobrir-se-á que o próprio problema só surgiu quando as condições materiais para resolvê-lo já existiam ou estavam pelo menos em vias de aparecer" (1973), consideramos que a relação entre a descentralização, a autonomia e a participação do cidadão, num processo de reorganização de serviços de saúde, é um daqueles problemas para os já existem as condições materiais para que sejam resolvidos.

A evolução da sociedade brasileira deu-se com a ampliação da cidadania política e social, ainda que de forma muito conflituosa. Coutinho (1989) considera que a classe dominante, que detinha o controle hegemônico do Estado, foi fazendo concessões à classe dominada, que, num processo de expansão de direitos políticos e sociais, criou espaços para a representação de novos interesses. Estudar o Estado nos possibilita entender, numa perspectiva de superação de lógicas até então vigentes, que relações são estabelecidas entre ele e a sociedade civil, e como essas relações poderá deslocar-se no sentido da sua ampliação e da hegemonia da sociedade civil.

Neste trabalho fizemos a opção pela abordagem desenvolvida por Gramsci acerca do Estado e da sociedade civil. Esta abordagem nos parece mais apropriada no contexto político e social brasileiro e nos permitiu delimitar o nosso eixo de análise. Assim sendo, resumimos o conceito de Estado da seguinte forma: "o Estado não é um fim em si mesmo, mas um aparelho, um instrumento; é o representante não de interesses universais, mas particulares; não é uma instituição acima da sociedade submetida, mas condicionada por esta e, desta forma, a ela subordinada; não é uma instituição permanente, mas transitória, destinada a desaparecer com a transformação da sociedade submetida" (Bobbio, 1977). A democratização e o fortalecimento da sociedade civil passam a ser necessidades de legitimação daquela "sociedade submetida". Gramsci, ao identificar um Estado em sentido amplo, apresenta-o em duas esferas principais: a sociedade política, "que se identifica com os aparelhos de coerção sob o controle das burocracias executivas e policial militar", e a sociedade civil, que é "o conjunto das organizações responsáveis pela elaboração e/ou difusão de ideologias" (Coutinho, 1981). Para Gramsci, o equilíbrio entre a sociedade civil e a sociedade política seria dado pela hegemonia de um determinado grupo social sobre toda a sociedade, hegemonia esta que seria exercida pelas "organizações ditas privadas" (Igrejas, sindicatos, escolas, etc.). "Não há hegemonia ou direção político-ideológica se não existirem as organizações que compõem a sociedade civil e se os interesses desta última não estiverem representados no Estado e influenciando a formulação de políticas públicas" (Coutinho, 1989).

A novidade deste novo enfoque é, para Coutinho (1981), que "a hegemonia, enquanto figura social, recebe agora uma base material própria, um espaço autônomo e específico de manifestação". O Estado não deixa de ser capitalista, por mais ampliado que seja, colocando-se um limite entre a plena cidadania política e social e o capitalismo (Coutinho, 1989).

Fazendo uma aproximação ao contex to latinoamericano de transição à democracia, no sentido de apontar algumas possibilidades de análise do Estado ampliado nas suas dimensões organizacionais a nível do setor saúde, encontramos na categoria "descentralização", associada às categorias "autonomia local" e "participação do cidadão" a forma concreta de identificação de um conjunto de determinações que, historicamente, foram se desenvolvendo para a construção de uma dada hegemonia.

A seguir, faremos algumas considerações sobre estas três categorias em separado, para poder visualisá-las melhor, embora tenhamos plena consciência da sua natural superposição. 


\section{DESCENTRALIZAÇÃO}

A organização dos serviços de saúde no Brasil e, poderíamos dizer, nos Estados latinoamericanos evoluiu conforme a compreensão de saúde das elites no poder (Teixeira, 1990). Esta afirmação está baseada na própria história da formação social brasileira. Teixeira, em seu estudo, mostra que alguns autores, na busca pelas raízes da característica centralizadora dos países latino-americanos, explicam esta situação a partir de quatro fatores causais. "O primeiro é a ausência de experiência feudal na tradição latino-americana; o segundo é a ausência do fenômeno de dissidência religiosa e o resultante centralismo latifundiário da religião dominante; o terceiro é a ausência de qualquer acontecimento ou circunstância, ao longo dos anos, comparável à Revolução Industrial européia; o quarto é a ausência daqueles aspectos da evolução ideológica, social, associados com a Revolução Francesa, que tão radicalmente têm transformado o caráter da sociedade européia ocidental durante o último século e meio" (Teixeira, 1990).

Concordamos com Teixeira que a explicação causal baseada na "ausência" de fatores "não resiste a um debate acadêmico", uma vez que cada formação social tem peculiaridades que não podem ser generalizadas, sendo conveniente respeitar suas heterogeneidades.

Existem, sim, várias interpretações acerca do significado da palavra "descentralização". O discurso oficial utiliza os termos "descentralização" e "desconcentração" como sinônimos. Na prática, o que se está executando é, exclusivamente, a dispersão físico-territorial das instituições localizadas no nível central, isto é, está sendo realizada a desconcentração. Um estudo recente (MPAS/Cepal, 1989) apresentou três vertentes possíveis onde a descentralização pode ser expressa. A primeira, da administração direta para a indireta, traz como conseqüência a proliferação de empresas públicas, sociedades de economia mista, autarquias, justificada pela necessidade de agilização das ações do governo. A partir daí ocorre o desenvolvimento de atividades que são do interesse público, sem qualquer controle por parte do próprio Estado. A segunda vertente seria a descentralização entre níveis de governo, onde localiza-se o maior percentual de demanda, devido, principalmente, ao fato de os estados e municípios terem perdido, nas últimas décadas, a sua capacidade de governo, em decorrência da centralização exagerada do Estado. O desdobramento deste tipo de descentralização dá-se na dimensão financeira - pela redistribuição de receitas públicas - e na dimensão político-institucional — pelas novas competências governamentais. A terceira vertente está refere-se à transferência de funções do setor público para o setor privado.

Embora o estudo acima faça aproximações importantes ao significado da descentralização no Estado brasileiro, ele ainda é parcial, por fazer esta identificação sob a ótica de um Estado restrito, isto é, enquanto sociedade política. Belmartino (1990) nos lembra que as propostas descentralizadoras, por terem raízes na história, também introduzem uma ambigüidade no seu significado: podem referir-se a uma distribuição real de poder ou a uma distribuição dos encargos estatais.

A nossa direção é no caminho proposto por Belmartino, isto é, no sentido de uma nova maneira de pensar a relação Estado/sociedade civil, em que a descentralização seja conseqüência de um Estado aberto, democrático, que supõe um cidadão que "seja eleitor, participante, supervisor, avaliador da prática de desenvolvimento e governo locais" (Belmartino, 1990).

\section{Autonomia}

Sabemos que, desde 1891, o Direito Constitucional brasileiro prevê a autonomia municipal em diversas áreas da administração pública. Entretanto, são várias as dificuldades que os municípios têm enfrentado, como, por exemplo, a escassez de recursos financeiros, como consequiência de uma forte concentração tributária, e a multiplicidade de encargos (delegação, do nível federal ou municipal, de atribuições impossíveis de executar).

No processo de modernização do Estado brasileiro, o modelo de desenvolvimento econômico adotado a partir da década de 60 provocou um esvaziamento financeiro e político dos municípios, tendo como conseqüência sua inoperância e uma centralização mais acentuada do poder do Estado. Desta forma, o sistema tributário brasileiro implantado com a Reforma 
de 1965 centralizou ainda mais os recursos nas mãos da União (Azeredo, 1989).

A perda de autonomia financeira e política dos estados e municípios trouxe como conseqüência a impossibilidade destes níveis de governo atenderem às necessidades da população, principalmente na área social.

A categoria "autonomia" tem sido utilizada no sentido de referir-se à autonomia financeira e administrativa de determinadas instituições em relação ao nível central. Para nós, o termo "autonomia" vai mais além. O conceito evoluiu da psicologia, cuja referência é a "preservação da integridade do eu" (Bonner, 1986), passando pelas ciências administrativas, enquanto uma "capacidade de autogestão nas dimensões administrativa e financeira" (Hodara, 1986), chegando ao significado atual, que é o de ser "uma consequiência da realização integral da democracia" (Coutinho, 1981). Significa, inclusive, a necessidade de superar a noção de nível local como organismo que dispensa, exclusivamente, serviços para a população. Esta superação dar-se-á com uma maior autonomia para deliberar sobre ações mais globais e, principalmente, referenciadas ao seu nível de atuação. A autonomia também caminha para um enfoque em que a defesa da identidade e dos espaços individuais se dá na busca do reequilíbrio entre os setores autônomo e heterônomo da sociedade, que conteríam os elementos de transformação social e da liberação do indivíduo (Gorz, 1987).

Concordamos com a tese de que "o conceito de autonomia supõe um poder de autodeterminação, de controle de oportunidades e conveniências regionais, sendo o oposto disso o que se observa nos Estados Administrativos, e que não pode coadunar com a realidade brasileira pela própria extensão e polimorfismo do território nacional. A autonomia consiste exatamente na faculdade de criar regras de direito próprias, adaptadas à realidade regional de acordo com as peculiaridades de cada município brasileiro" (Santos \& Ballone, s.d.).

Borja, fazendo uma revisão das experiências realizadas nos países europeus, aponta alguns efeitos perversos da proposta de descentralização e faz uma lista de propostas organizativas. Nos aspectos referentes à autonomia do nível local, onde está colocado bem claramente a estreita relação entre a descentralização e a autonomia local, "sobressai a conveniência de respeitar a heterogeneidade das condições locais e a tensão resultante da necessidade de estabelecer articulações que vinculem as instituições locais e regionais com a administração central" (Belmartino, 1990).

\section{Participação}

Tomando por base a análise realizada por Souza (1990), que considera a temática dos movimentos sociais e sua expressão na saúde ainda marginal no campo da saúde coletiva, procuraremos apresentar, resumidamente, a evolução da participação do cidadão enquanto forma de expressão da socidade civil em assuntos que lhe são de direito.

Bohadana (1982) observou que as práticas referidas à participação social vêm se apresentando em duas perspectivas: a primeira, "a partir dos efeitos a nível da consciência social das populações atingidas", sendo vista como instrumento para a educação popular; a segunda, "a partir dos seus efeitos em melhorar a saúde da população", expressando-se como objetivo finalista de melhoria do nível de saúde da população. Bohadana faz uma interessante análise dos alcances e limites dessas duas perspectivas. Entretanto, interessa-nos entender como elas evoluíram no sentido de sua complementariedade, com conseqüente ampliação do significado da categoria em questão.

A categoria "participação" está, a nosso ver, intimamente relacionada à categoria de democratização. Em sociologia, o termo "participação" é utilizado para "indicar a natureza e o grau de incorporação do indivíduo ao grupo". De acordo com Costa (1989), a história recente da participação social tem-se expressado a partir dos conflitos originados pelas contradições decorrentes da "incapacidade do capitalismo brasileiro de resolver as novas e sempre crescentes necessidades postas à reprodução da força de trabalho" e "do estilo de política urbana do Estado, baseada em inversões públicas rentáveis à reprodução do capital". Nos países em desenvolvimento utiliza-se o conceito de participação política para indicar cidadania. Entrando num terreno ainda pouco aprofundado e, como diz Weffort (Costa, 1989), ainda para 
ser feita a sua história, que é o da participação social enquanto exercício da cidadania, utilizaremos a expressão "participação do cidadão" para designar o interlocutor que estabelece a relação entre o Estado e a sociedade civil, embora Costa (1989) lembre que, no capitalismo, ainda não foram registradas experiências de participação onde estivessem incluídos mecanismos coletivos de controle do poder estatal por parte da classe trabalhadora enquanto força hegemônica no campo institucional, isto é, onde efetivamente ocorresse a ampliação da cidadania e, conseqüentemente, do Estado. O interlocutor, isto é, o cidadão, passa a ter direitos onde antes existia "apenas um genérico interesse ou necessidade que não tinha valor em relação a ninguém" (Rodotá, 1989).

Os limites e as possibilidades desta integração entre a descentralização e a autonomia dos serviços estarão mais claros na medida em que identifiquemos como o movimento social, enquanto sociedade civil, se constrói no sentido de se tornar mais coletivo e, conseqüentemente, hegemônico.

E fazendo nossas as palavras de Stefanini (1980), a partir da experiência de participação democrática na programação econômica e social na Itália: "uma obra dessa natureza pode ser realizada se em torno dos poderes públicos crescer uma participação de forças políticas e grupos sociais que concorram para definir objetivos gerais e particulares, se o consenso (grifo nosso) for conquistado em torno destes objetivos e com instrumentos para alcançá-los”.

\section{Idéias para Aprofundar}

Realizar a descentralização dos serviços de saúde sem, concomitantemente, aumentar a capacidade de decisão local (autonomia) e o controle (participação), a nosso ver, não representa uma real distribuição de poder. A identificação das possíveis determinações e limites de uma descentralização dos serviços inseparável de uma maior autonomia local e de um maior grau de participação é uma tarefa necessária.

Surgem, assim, algumas hipóteses que estão relacionadas às três categorias apresentadas acima: o processo de descentralização só pode ocorrer quando o Estado tem características descentralizadoras; a autonomia local é uma das condições básicas no processo de democratização da sociedade; e, finalmente, a participação do cidadão deve atuar como principal interface entre o processo de descentralização e o de autonomia local. Esta tarefa nos impomos a partir de agora.

\section{RESUMO}

GAWRYSZEWSKI, V. Reorganização dos Serviços de Saúde: Algumas Considerações Acerca da Relação entre a Descentralização, Autonomia Local e a Participação do Cidadão. Cad. Saúde Públ., Rio de Janeiro, 9 (2): 210-215, abr/jun, 1993.

Neste artigo são feitas algumas considerações históricas e teóricas acerca das categorias "descentralização", "autonomia local" e "participação do cidadão" no estudo do processo de reorganização dos serviços de saúde. Considera-se a necessidade de aprofundarem-se os estudos, no sentido de estabelecer os determinantes e os limites de uma descentralização dos serviços de saúde associada a uma maior autonomia local e a uma maior participação do cidadão. São sugeridas algumas hipóteses e a forma como desenvolvê-las.

Palavras-Chave: Reorganização de Serviços de Saúde; Descentralização de Serviços

\section{REFERÊNCIAS BIBLIOGRÁFICAS}

AZEREDO, B., 1989. As Mudanças Constitucionais e o Financiamento dos Programas Sociais. Rio de Janeiro. (Mimeo.)

BELMARTINO, S., 1990. Políticas neoliberales en salud: la discussión de una alternativa. Divulgação em Saúde para Debate, 2: 33-37.

BOBBIO, N., 1977. Gramsci e la Concezione della Società Civile. $3^{\mathrm{a}}$ ed., Milano: Feltrinelli.

BOHADANA, E., 1982. Experiências de participação popular em ações de saúde. In: Saúde e Trabalho no Brasil (R. A. Pego, Coord.), pp. 105-128, Petrópolis: Vozes/Ibase.

BONNER, H., 1986. Autonomia. In: Dicionário de Ciências Sociais (B. Silva, coord.), p. 104, Rio de Janeiro: Fundação Getúlio Vargas. 
COSTA, N. R., 1989. Transição e movimentos sociais: Contribuição ao debate da Reforma Sanitária. In: Demandas Populares, Políticas Públicas e Saúde (N. R. Costa; M. C. S. Minayo; C. L. Ramos \& E. N. Stotz, orgs.), vol I, pp. 45-65, Petrópolis: Vozes/Abrasco.

COUTINHO, C. N., 1981. Gramsci. Porto Alegre: LPM.

1989. Representações de interesses, formulação de políticas e hegemonia. In: Reforma Sanitária: em Busca de uma Teoria (S. F. Teixeira, org.), pp. 47-60, São Paulo: Cortez/Abrasco.

GORZ, A., 1987. A deus ao Proletariado: para Além do Socialismo. Rio de Janeiro: Forense Universitária.

HODARA, J., 1986. Autonomia Universitária. In: Dicionário de Ciências Sociais (B. Silva, coord.), p. 104, Rio de Janeiro: Fundação Getúlio Vargas.

MARX, K., 1973. Contribuição para a Crítica da Economia Política. Lisboa: Estampa.
MPAS (Ministério da Previdência e Assistência Social); CEPAL (Comissão Econômica para a América Latina), 1989. A Política Social em Tempo de Crise: Articulação Institucional e Descentralização. Brasília: CEPAL.

RODOTÁ, S., 1989. A Constituinte de 89 a 89. Revista Isto é - A Revolução Francesa, $9^{\circ}$ fasciculo, pp. 138-149, junho de 1989.

SANTOS, N. R. \& BALlONE, G. T., s.d. Autonomia Municipal e Saúde. São Paulo. (Mimeo.)

SOUZA, L. R., 1990. Movimentos de Saúde: Dificuldades à sua apreensão. Saúde em Debate, 29: 48-51.

STEFANINI, M., 1980. Il decentramento e la partecipazione democratica. In: I Consigli di Quartiere. Decentramento e Partecipazione Democratica (G. Morales; G. Longo \& M. Stefanini, eds.), pp. 9-42, Roma: Ed. delle Autonomie.

TEIXEIRA, S. M. F., 1990. Descentralização dos serviços de saúde: dimensões analíticas. Revista de Administração Pública, 24: 79-99. 